\title{
Development of Grammatical Knowledge for Communication Activities for Foreign Language Acquisition in Online Classroom for Preparatory Year of Romanian Language at the University of Pitești
}

\author{
Aurora Tatiana Dina \\ University of Pitesti \\ Dănuța Magdalena Pruneanu \\ University of Pitești \\ Ana Cristina Lemnaru \\ University of Pitești
}

\begin{abstract}
The paper focuses on developing grammatical knowledge for communication activities, through interactive sample activities in the online classroom, in the process of Romanian language acquisition as a foreign language of study for young adults, between 18 - 21 years of age, who apply for the Preparatory year of Romanian language at the University of Pitești, Romania. Teaching grammar has always been a challenge in every teaching-learning process of a foreign language. Grammar grounded knowledge is the key for communication in terms of accuracy and fluency, because it is important for learners to have a set of rules and constructions to make use of, in order to develop interactive and communicative abilities. Each set of activities focusing on accuracy or on fluency used to create correct examples of language use, requires adaptation to the communicative needs, depending on the level of the learners and their needs. Recent national and international events make it clear that there is an imperative need to adjust the entire process of delivering communicative grammatical content in order to make grammar become functional at the level of online communication the learners have to achieve. The goal during online classes is to use targeted communicative practice activities and performative tasks that best facilitate communicative grammar comprehension and learning, in order to help young adult learners gain confidence to start speaking and communicate online.
\end{abstract}

Keywords: grammatical knowledge, communication activities, preparatory year, Romanian language, online classroom

\section{Introduction}

We are facing the birth of a new society defined by different patterns of communication, a different perception of space and time, where everyone can access and use the online environment, regardless of age, gender, social class and geographical context. The 
continuously - growing need for acquiring communication skills in a foreign language is fully justified, since it opens new doors in terms of employment, and it also allows you the opportunity to know new cultures, people and places. This ongoing technological progress and changes in the knowledge-based society is challenging the educators and trainers to rethink what they teach, to whom, how and when. The world has gradually changed so surprisingly over the last 10 years, that we, as teachers, have to ask ourselves if our traditional way of organizing education really meets the needs of today's learners. In order to prepare ourselves to teach a changing audience - the digital generation - we had to use pedagogical strategies that strengthen the quality of the learning process. We managed to attract our learners by doing a systematic rethinking of the teaching methods, by redefining the learning concepts, by introducing new innovative elements besides the students' textbooks, by reshaping learning approaches.

The main aim of this article is to investigate how the Romanian grammar teaching and learning is carried out in the process of Romanian language acquisition as a foreign language of study for the Preparatory year of Romanian language academic courses at the University of Pitesti, Romania; to focus on grammar content from the students' textbook, and to present a sample of interactive targeted communicative activities as well as some performative tasks meant to engage students in spontaneous communication. To fulfil our aim, we have the following main research objectives, which we will explore in the present article, by applying questionnaire and by taking interviews: for the first part of our analysis we will discuss about the grammar content in the students' textbook, language teachers' attitude on grammar instruction process for communicative purposes; the last part of the analysis will present the effects of the methods and activities used to improve students' communicative performance.

\section{Brief Outline of the Methods and Approaches for Language Learning and Teaching}

\subsection{The Grammar Translation Method}

The Grammar Translation Method is the classical method, considered simple and effective (Stern, 1996), whose main objectives are the study of grammar, vocabulary and literature. The approach is a deductive one, with the emphasis on conscious learning. The ability to receive the written message and the ability to express oneself in written are the most practiced skills. The native language of the students is extensively used, the techniques used being translations, reading texts, grammar exercises and vocabulary. The roles of the teacher are as follows: manager, coordinator and evaluator of the students, the interaction in the classroom taking place especially between the teacher and the students (frontal approach). Correcting students is very important because the emphasis is on accuracy.

\subsection{The Direct Method}

The inventor of the method is C. Berlitz. The main objective is to teach students to communicate in a foreign language. Translation is not allowed, the teacher using the real world, images, pantomime to suggest meaning. The mother tongue is not used at all. Grammar is taught inductively. Students practice vocabulary in context. The techniques used are: conversation, reading aloud, exercises, compositions, repetitions. The teacher's role is to be a partner of the student. The interaction takes place between the teacher and the students, but also between the students and the students. 


\subsection{Presentation, Practice, Production ( PPP)}

This is the British version of the audio-lingual method, notes Jeremy Harmer (2004, p. 80). It consists of three stages. In the first stage the teacher introduces the elements of language to be assimilated. Students practice using reproductive and rehearsal techniques. The third stage concerns the use of language presented and assimilated in an original and authentic way by the students. As with the audio-lingual method, vocabulary and grammar are taught inductively. Communication takes precedence, since the mother tongue is not used. The model is the teacher, who is the one who coordinates the activity. Because it is a method based on communication and evaluation is done all this way.

\subsection{The Communicative Approach}

The Communicative Approach or Communicative Language Teaching ( CLT) has as main objective is students' fluency. Emphasis is placed on "real" communication (Harmer, 2004, p. 85). All four dimensions of language teaching are developed: the ability to express oral expression, the ability to receive the oral message, the ability to receive the written message and the ability to express oneself in writing. The learners' communicative skills are developed by linking grammatical development to the ability to communicate. Grammar is taught in relation to a communicative task, thus creating a need for specific items of grammar. The students' mother tongue is not used. The techniques used are: discussions, debates, roleplaying, written communicative activities, drama, etc. The roles of the teacher are those of facilitator and manager of the students' activity, but also of their partner, the interaction taking place especially between students. Authentic and interesting materials are used in order for the students to make connections with their own language and culture. Errors are tolerated especially during communication activities, when the emphasis is on fluency. Students are evaluated both orally and in writing.

\section{Research Design and Procedures}

For the first analysis part we have discussed the role of grammar teaching, with reference to the communicative activities in a second language acquisition process, then we made an analysis of grammar and grammar exercises in the students' textbook for Romanian language which we use at the academic preparatory year of Romanian language in our university. In order to find out the teachers of languages' opinion about grammar teaching for communicative activities as well as about the teaching aids and educational materials used during online classes to make the methods and approaches for teaching a foreign language more interesting, we applied some questionnaires and interviewed them. For the last part, during online classes, we gave the students a task to complete : exercises with interactive targeted communicative activities, and we compared the answers given by the students when they were interviewed about how they understood better the concept and the use of grammar rules, with their academic results of the respective practice communicative activities.

\subsection{The Role of Grammar Teaching for Communicative Activities}

Grammar is at the heart of spoken and written communication and allows us to be clearly understood by others. Teaching grammar is fundamental in the process of acquiring a foreign language. Without grammar we can hardly speak, and if we do, it will not be very correct and concrete. Grammar has long been a subject of study and although the methods of studying grammar have changed dramatically lately, the reasons for studying grammar have remained 
essentially the same. Grammar allows people to communicate what they want to express in a way that can be understood clearly. Explicit knowledge of grammar is very important, as it gives us a more conscious control and choice over the language. By fostering explicit knowledge of grammar, performative tasks will hopefully become implicit over time. Poor use of grammar can lead to blurring of messages, which affects our ability to communicate and can hinder the strengthening of relationships - an important skill for the development of young people. The correct use of grammar, on the other hand, makes listening and reading easier, making communication more enjoyable and impact more positively on relationships. Grammatical competence is defined in the CEF as follows: "... knowledge of, and ability to use, the grammatical resources of a language[...]. Grammatical competence is the ability to understand and express meaning by producing and recognizing well-formed phrases and sentences in accordance with these principles (as opposed to memorizing and reproducing them as fixed formulae)." (Council of Europe, 2001, pp112-113).By teaching grammar, young people become even better prepared for the world of work. Discussion on how to teach grammar effectively and how to provide effective grammar practice for students has always been a major concern for both language teachers and learners. In order to make a grammar instruction meaningful, there are some reason to take into consideration: students need to think critically when given grammar concepts and rules; they have a better understanding of grammar if the grammar instruction is sequenced; students need regular practice of what they are being taught; students need to acquire grammatical skills that will allow them to be able to transfer their comprehension of grammar knowledge to reading, writing, and real life. Brown (2001) mentioned that grammar should be taught in accurate communicative contexts, thus encouraging fluency and accuracy. He also offered a set of guidelines for teaching grammar for effective communication: simple explanations, clear examples, relevant visual teaching aid; grammar should be presented in an interesting, motivating way for the students, taking into account learners' cognitive style, as well.

\subsection{An Analysis of Grammar Structure in the Students' Textbook}

We will examine the techniques used for grammar teaching and learning in classrooms, also grammar content in students' textbooks. Şerban V. and Ardelean L. (1980), argue that the structure of teaching and learning a grammatical phenomenon should comprise five stages:

1. Preparatory dialogue with complete semantics of forms.

2. Presentation of forms in context (structuring phase).

3. Structural assignation exercises (exercise / practice phase).

4. Functional exercises (generalization phase).

5. 5.Integrating the phenomenon into micro-conversation (skills training).

Our students' textbook for Romanian language as a foreign language, called 'Limba română Manual pentru studenții străini din anul pregătitor", whose authors we are, generally follow this line; language structures are taught in close connection with vocabulary and grammar elements, and are exemplified on texts. The introductory part is dedicated to phonetics, with oral teaching, in order to clarify the issues related to the target language sounds; teaching is sequenced then into reading, writing, grammar and vocabulary, and, eventually, fluent speech. As structure, it comprises complete units, the grammatical category being associated with the appropriate theme, and the act of speech, being related to the thematic area; the lexical and grammatical components is presented and explained and then integrated into communication structures ; a theme such as "In the city" can be used for teaching the forms of the adjective, 
and the description of means of transportation in the teaching of the demonstrative pronoun and adjective. The clearly formulated objectives of the unit are presented at the beginning of each lesson. Romanian grammar is presented in a clear manner, with very short and comprehensive structures, with rules displayed in a simple manner; the morphology, syntax is structured according to the level of speech, progressively, so that the learners may acquire a proper vocabulary, which, together with a set of grammar rules, will allow them to become engaged in further communicative activities. The exercises are very simply presented, especially at the beginning, by setting a demonstrative model as example. Grammar exercises are generally based on the model: first is shown an item with a given answer as example, and then a number of eight to twelve similar items are given to be solved. In addition, dictation and grammatical compositions are used.

\subsection{A View of Teachers' Attitude Towards Teaching Grammar for Communicative Purposes}

In the process of second language teaching, teachers are supposed to use participative techniques and apply suitable strategies so that their students can produce the spoken language in an acceptable way, as well as to contribute to the increase of the activeness, creativeness and productiveness of learning among students. At the same time, we refer to the students who should have a good level of oral fluency, after having been introduced to the most appropriate techniques for developing the oral fluency, along with grammatical accuracy, thus being able to determinate the achievement in their communication activities, whether effective or not. We applied a questionnaire and we also interviewed the 12 teachers, aged between 45 to 65 years of age, $85 \%$ out of whom are female teachers, that deliver courses of Romanian language as a foreign language, to find out what is the way grammar should be taught in the classroom, and to present several situations that describe how teachers of languages make use of several methods, techniques and approaches, and what is the type of targeted oriented practice activities, performative tasks they use, in order to prove the efficacy of grammar instruction as a necessary step towards meaningful communication. The questions that teachers were required to answer in the questionnaire referred to the language used in grammar teaching, to what are the methods and techniques used for teaching Romanian as a foreign language, as well as of teaching grammar, and also to specify the tools and resources (teaching aids and educational materials) they used for online practice of communication activities in the online classes. For the interview part we enquired, teachers discussed the advantages and disadvantages of the methods and approaches they used for teaching grammar for communicative purposes, and also about the benefits and barriers of the tools and resources they used in online classroom.

The question that referred to the language used in grammar teaching: "Do you think Romanian grammar should be taught in Romanian, in the link language, or in both?" revealed the following answers: when enquired if grammar should be taught in Romanian or with the help of the link language ( English or French) or both, $65 \%$ of teachers agreed to use them both. $10 \%$ of the teachers answered that grammar should be taught only in Romanian, so that teachers have the chance to listen to the target language, while $25 \%$ thought that grammar should be taught only with the help of the link language, because it is easier for the students to understand the rules. 


\section{Language used for grammar teaching}

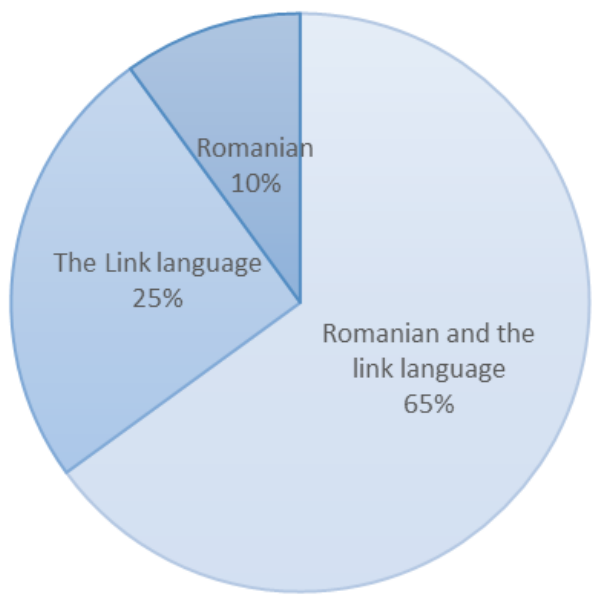

$\square$ Romanian and the link language $\quad \square$ The linklanguage $\quad \square$ Romanian

Figure 1 - Language used for grammar teaching

For the question, about what are the methods and techniques used for teaching Romanian as a foreign language, we asked the question: "Which approach do you use to present grammar content?", and we also made interviews about teaching methods and approaches for teaching grammar. The investigation focused on two topics: the methods of grammar teaching, the relationships between correct grammar and communicative competence. We know there are two main approaches of teaching grammar. The deductive approach, more teacher - centred, when the teacher gives the rule, and language is produced based on the rule, and the inductive approach, more student - centred, when the teacher gives the students a means to discover the rule by themselves. As it is also written in the questionnaire, we asked teachers which approach do they use when teaching grammar, the deductive one, which includes PPP, Grammar Translation Method, the inductive one, which includes The Direct Method, The Communicative Method, or a mix of these types of approaches. We can see that when the teachers taught new grammar content in the classroom, $25 \%$ of teachers used only inductive approaches, because it consolidates students' oral as well as written abilities. $70 \%$ of the teachers used both inductive and deductive approaches in their classrooms: they used inductive approaches when a new grammar topic was first introduced and followed up with deductive approaches when the topic was reviewed. Only $5 \%$ of teachers used the deductive approach. Figure 2, down below, shows a graphical representation of the answers of the language teachers, regarding the teaching approach for grammar content. 


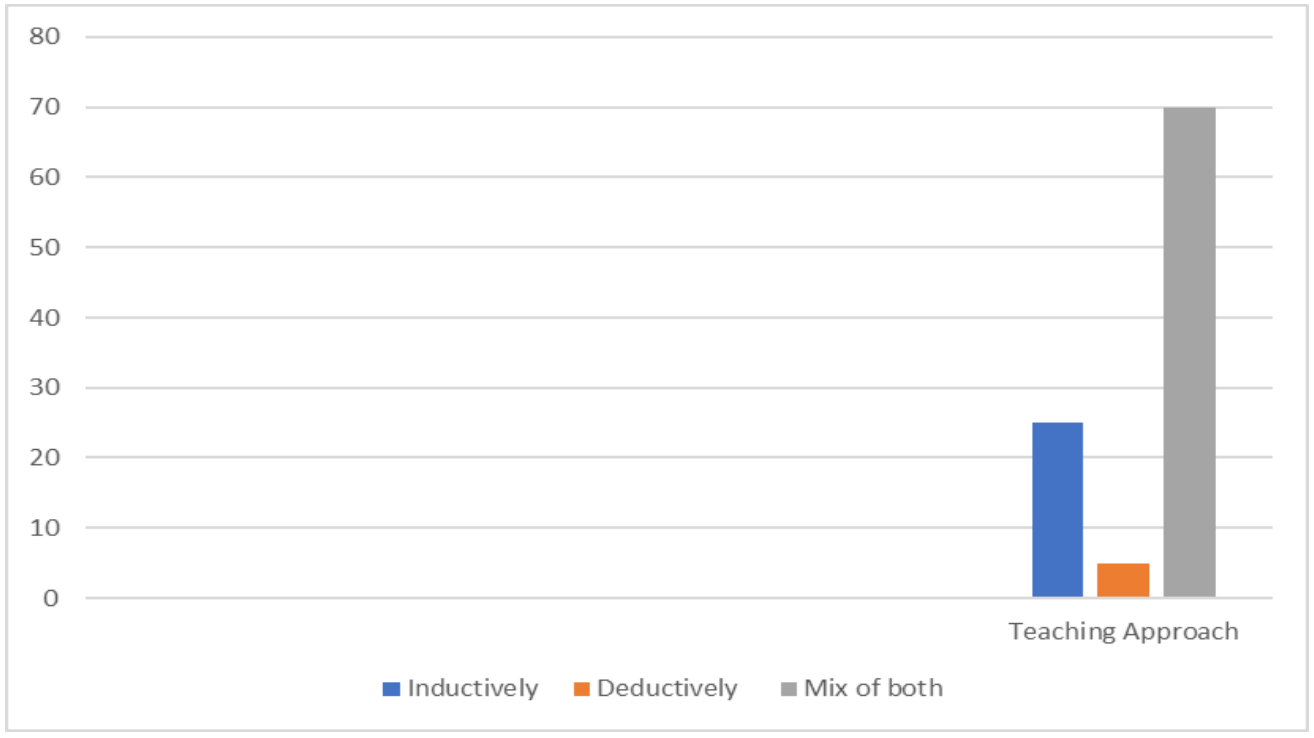

Figure 3 - Teaching approach for grammar content

We shall further discuss three different situations of teaching that we were presented during the interviews, and then we shall explain the advantages and disadvantages of using these methods and approaches for communicative purposes during classes of Romanian language as a foreign language. This is in addition to the questionnaires, but the findings are coincident. Situation 1: the teacher explains to the students what will be expected during the task and post task review section. The teacher introduces, or reviews, as is the case, the main vocabulary and grammatical items the students will need to accomplish the assigned task. This is Presentation, Practice, Performance (PPP), a deductive approach whose main advantage is that it is easy to implement, because production comes only after presentation and practice, it allows the possibility to prime language for later use. One of the main disadvantages is that is deprives students of learning opportunities, because they may become unsure on how to use target language in different contexts.

Situation 2: the teacher uses pictures and images to teach new words, speaks only in Romanian ( the target language), reads a passage in the text, then he asks the students questions related to that passage, and ends the lesson in an attractive way for the students, by telling a poem. The Direct Method, here presented, is a method which has very great impact in language teaching, hence the oral and natural techniques used have as main aim acquisition of the language by associating the word with the action, without involving mother tongue. This method ignores written work and reading activities. There is not sufficient attention paid to reading and writing skills.

Situation 3: the teacher asks students to repeat the sentences he uttered; the expressions are learnt by using the dialogue based on imaginary situations; after the sentences are repeated and memorised, students work in pairs, then they are introduced the model exercise, they copy the exercise. This is mix of the deductive and inductive approaches, in the desire to cover reading, listening, writing and oral performance. 
The research findings indicate that teachers' perceptions about grammar and grammar teaching is that students should be able to express their own ideas in real situations in a language that is as correct, meaningful and appropriate as possible, their task being to facilitate this grammatical skill with maximum efficiency. Teachers' role is to guide students on how to make use of the patterns of grammatical form in contexts of communicative activities. Learners, in their turn, should learn grammar implicitly through target language use and explicitly through the discovery of grammatical rules through use in meaningful examples.

For the question "what are the teaching aids and educational materials you used for the targeted communicative activities during online classes?" we inquired about the tools and resources, , they were required to choose from a variety of items and solutions available for online language teaching. Traditionally, language teachers use textbooks as an essential tool for teaching and learning that supplement teacher instruction. Foreign language learners use the textbook as a qualitative source of learning with language other than input given by the teacher. Given the present situation, the attention shifted to a more adequate way of delivering courses, introducing new, interactive teaching tools and educational resources and using proper methods and approaches to help the students be ready for the instruction that will allow them to communicate.

It resulted that teachers are more interested in the digital content, especially the one that is interactive for several reasons: it is more attractive to the student, it contains built-in audio and video, the student feels more involved in the learning process, it also offers the opportunity for the completed exercises to be corrected automatically, as well as the information necessary to accomplish the targeted practice activities, such as a glossary or grammar reference, it engages students into a friendly learning environment, so as to gain confidence and start speaking.

Figure 3 shows the teachers' preference for several types of digital content:

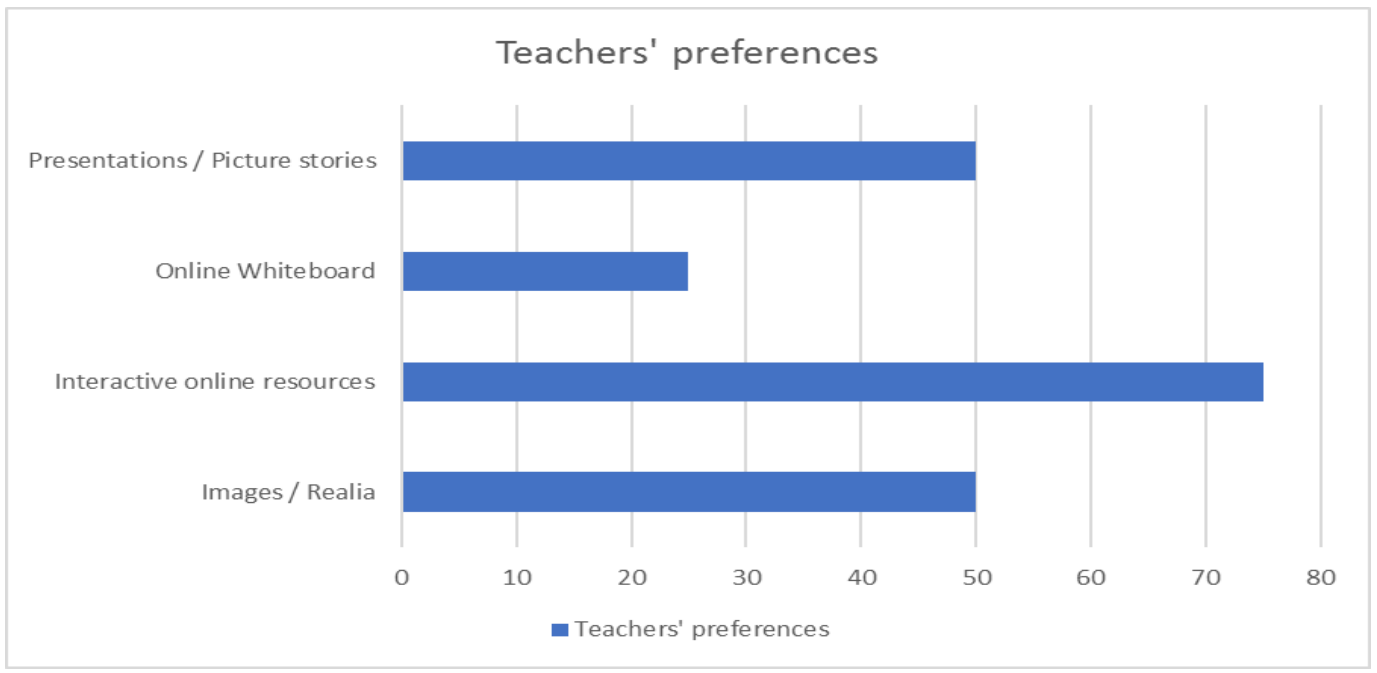

Besides the preferences resulted from the questions of the questionnaire, we asked the teachers to motivate their choice. The interactive online tools and resources are preferred in $75 \%$ cases in online teaching. They said they represent an extraordinary solution: the video 
clips on different virtual platforms can be viewed by students, for communicative purposes, and later on they can complete worksheets, created mainly by the teachers; or, some interactive live worksheets, created entirely by the teacher, quiz, which offer a useful feedback, not only to the students, but also to the teachers, who can have an easier and clearer record of the students' personal progress. With an equal percent of $50 \%$, teachers make use of picture stories and presentation; in the same way, they use Realia or images when they introduce new vocabulary or grammar, or as a starting point for communication activities; these kind of activities make students feel motivated and become actively involved in the online class. Power Point Presentations, as well as Picture stories represent a support for the student teacher interaction. Picture stories are usually a starting point for a narrative speaking or a writing activity, but they can also be of utmost importance in the communicative and interactive classroom. The Power Point Presentations can be very dynamic, attractive and interesting, especially if the teacher succeeds in combining successfully the text, the images, the audio, the video to present new material to the students. Another advantage is the fact that, once it is distributed, it can be accessed by the students any time, at will. There was only $25 \%$ preference for the online whiteboard. The use of such a software brings a lot of benefits, by creating an attractive environment for real collaboration during online classes, by allowing possibility for all participants to write and draw at the same time and also to see in real time the changes made, by offering easy access to other online applications or digital content. The lack of choice for this e-tool is due to the fact that during face - to - face classes, the classical whiteboard was the main tool used for collaborative activities, while at the online classes, both teachers and students have much more opportunities and choices among all the other interactive resources and digital tools.

\subsection{Grammar Teaching in Practice in Online Classroom}

In terms of grammar teaching practice for communicative purposes, we propose a set of targeted interactive-learning activities for young adults between 18 - 21 years of age, during online classes at the Preparatory year of Romanian language, with the purpose of developing communication abilities, increasing learning efficiency and building positive interpersonal relationships. We shall present a sample - activity of this type we applied to all the groups of students. It is an activity in which the learner is pushed to speak on a topic using, at the same time, grammar rules.

Figure 4 presents a sample of a targeted communicative activity, an interactive worksheet, presented during online classes, which is the starting point for engaging students into spontaneous authentic communication. 
1.Completează . in exemplele următoare, cu prepozițiile din chenarul de mai jos corespunzătoare, pentru a forma propoziții corecte.

in, la, din, de la, pe, spre

2. Citește fiecare propoziție și bifează dacă este adevărat sau fals in cazul tău. notând $A$ sau $F$ in coloana marcată .. $T U^{\prime \prime}$.

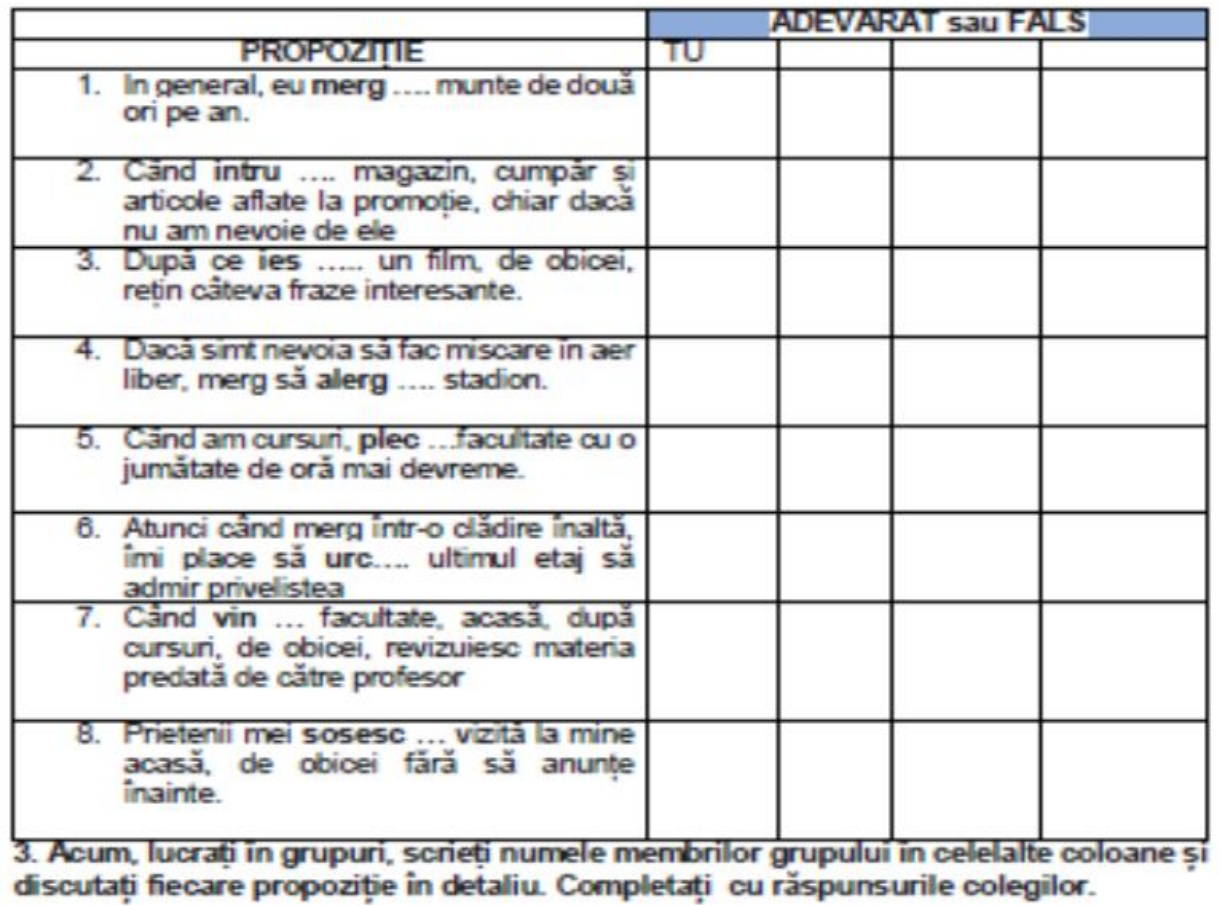

Figure 4 A sample of interactive targeted communicative activity

In this verbs of movement with obligatory preposition activity, students learn 8 verbs of movement with obligatory preposition and use them in a virtual group discussion. We put the interactive worksheet on the classroom platform. Students begin by completing verbs of movement with obligatory preposition task in 8 statements, with the prepositions shown on the interactive worksheet. When the students have finished, they are automatically given the answers; then, we review each verb verbs of movement with obligatory preposition and the meaning of each statement. Next, students read each statement and indicate whether it is true for them or not by writing 'A' for true or ' $F$ ' for false in the column marked "TU". After that, we divide the students into groups of four. One student from each group is designated to write the names of their group members in the other columns of the chart. The students then discuss each statement in detail and the designated student from each group completes the chart with their classmates' true or false answers. Afterwards, we have a class feedback session to find out which statements were true for most of the students and which were false. Any interesting findings can then be discussed in more detail. 
This type of activities are more practical and conversation-focused. Their aim is to stimulate the use of grammar and vocabulary the students have learnt. These activities should enhance different skills altogether: team working, communication in a foreign language, public skills, problem-solving, creative thinking etc. Through targeted communicative activities, interaction and group work are encouraged, increasing the learner's self-esteem and ability to organize and learn autonomously. These activities help learners use the language in various areas, focusing more on communication. Furthermore, the choice of the topic is crucial, and also a certain relaxation, on the teacher's part, with regard to testing.

The results returned from these type of activities, together with the answers given by the fifteen interviewed students showed that grammar understanding was inversely proportional to grammatical errors made in exercises. The greater the level of understanding the students had, the more correct answers they tended to give. Moreover, the competency level in listening, speaking, reading, writing and grammatical understanding are different primarily because of the different teaching approaches used.

\section{Concluding Remarks}

This article evaluated several teaching approaches, to determine which method is the most appropriate for the purposes of teaching and learning Romanian grammar for the Preparatory year of Romanian language academic courses at the University of Pitesti for the courses delivered during online classes. Furthermore, in order to understand how grammar is presented in the students' textbook, we studied the grammar section of the students' textbooks, and we examined the ways of grammar teaching and learning in the classroom, and how the exercises are displayed in textbooks. After that, to learn more about the teachers' view towards teaching grammar for Romanian as a foreign language, we presented some situations in which the teachers demonstrated how they used the teaching methods and grammar instruction in the classroom, making observations for the methods chosen. To determine if a specific teaching method and grammar instruction technique can enhance oral performance, we examined the effectiveness of the targeted interactive practice activities and performance tasks via interviews with the students and by comparing their answers with their academic results obtained in the online classes. The analysis of the teaching methods, the grammar and grammar exercises form the students' book, the teachers' preference for some digital tools and online resources for their online class, together with the level of oral performance of the learners of Romanian as a foreign language, has yielded several results. Practice showed that students were exposed to the both learning approaches, inductive and deductive, in order to develop their listening, reading, writing, speaking abilities as well as to gain grammatical knowledge. At the same time, the new virtual environment created a new context where they were more willing to interact and communicate, especially if the teacher adapted the methods and approaches to the online classes. So, no matter how relevant the students' book are, the teacher's methods and approaches have the greatest impact on students' learning, on their engagement in dicussions, on their level of grammar accuracy and oral fluency for any performative tasks or targeted communicative activities.

The conclusion that emerges after conducting the analysis through both questionnaires and interviews is that in general, the teachers possess positive attitudes towards grammar teaching. They believe grammar is useful and important for understanding the structure of the Romanian language and for communicative purposes. 


\section{References}

[1] Brown, H. D. (2001). Teaching by principles: An interactive approach to language pedagogy. New-York: Longman

[2] Council of Europe (2001). Common European Framework of Reference for Languages: Learning, Teaching, Assessment. Cambridge: Cambridge University Press, pp 112- 113

[3] Harmer, J. (2004). The Practice of English Language Teaching. London: Longman, p 85

[4] Stern, H. H. (1996). Fundamental Concepts of Language Teaching. Oxford: Oxford University Press,

[5] Şerban, V, Ardelean, L (1980). Metodica limbii române. Curs intensiv pentru studenţii străini, Editura Didactică și Pedagogică, București, p.43

\section{Appendix}

Questionnare for the Teachers

1.Do you think Romanian grammar should be taught in Romanian, in the link language, or in both?

Romanian

Link language

Both

2. Which approach do you use to present grammar content?

Inductive approach

Deductive approach

A mix of approaches

4.What are the teaching aids and educational materials you used for the targeted communicative activities during online classes?

Realia / Images

Power Point Presentation / Picture stories

Online Whiteboard

Interactive online resources (interactive worksheets, videoclips, quiz) 